\title{
Programmed Labor in Gestational Diabetes Mellitus as a Reserve for Reducing the Frequency of Cesarean Section
}

\author{
Agamurad A. Orazmuradov ${ }^{1}, \mathrm{PhD}, \mathrm{ScD}$; Marina B. Khamoshina ${ }^{1}, \mathrm{PhD}, \mathrm{ScD}$; Anastasiya \\ N. Akhmatova ${ }^{1}, \mathrm{PhD}$; Irina V. Bekbaeva ${ }^{1 *}$; Gayane A. Arakelyan ${ }^{1}$; Zh. Z. Suleymanova ${ }^{1}$; \\ Khalid Haddad $^{1}$; Sergey I. Kyrtikov'; Alina A. Sazhina'; Aleksey A. Lukaev², PhD \\ 'Peoples' Friendship University of Russia (RUDN University), Moscow Russia \\ ${ }^{2}$ Mytishchi City Clinical Hospital Mytishchi, Moscow Region, Russia
}

\begin{abstract}
The aim of this study was to investigate the perinatal outcomes of delivery by various methods in patients with gestational diabetes mellitus (GDM).

Methods and Results: The study included 403 pregnant women (gestational age of 37.0-41.0 weeks) with GDM and 68 without disorders of carbohydrate metabolism, who gave birth from the second quarter of 2018 to the third quarter of 2020 in the maternity ward of the City Clinical Hospital No. 29 named after N.E. Bauman. All patients with GDM were divided into 2 groups. Group 1 included 187 patients receiving insulin therapy; Group 2 included 216 patients receiving a well-balanced diet. The main indicators of the health status of newborns in the early neonatal period were assessed taking into account the methods of delivery: programmed labor (PL), planned cesarean section (PCS), and spontaneous delivery.

The 1-minute Apgar score in newborns from mothers of Groups 1 and 2 was higher at the PL, compared with PCS. The 5-minute Apgar score in newborns from mothers of Group 2 was also statistically significantly higher at the PL, compared with planned CS. The incidence of hypoglycemia in newborns from mothers of all groups was minimal at the PL, including a statistically significant low rate in newborns from mothers of Group 1. Symptoms of neonatal CNS depression were significantly more common in newborns born by abdominal delivery from mothers with GDM.

Conclusion: PL in women with GDM reduces the incidence of the main complications of the early neonatal period: hypoglycemia and symptoms of neonatal CNS depression. PL may be considered more acceptable than abdominal delivery for women with GDM.(International Journal of Biomedicine. 2021;11(2):156-159.)
\end{abstract}

Key Words: gestational diabetes mellitus • programmed labor • cesarean section

For citation: Orazmuradov AA, Khamoshina MB, Akhmatova AN, Bekbaeva IV, Arakelyan GA, Suleymanova ZhZ, Haddad Kh, Kyrtikov SI, Sazhina AA, Lukaev AA. Programmed Labor in Gestational Diabetes Mellitus as a Reserve for Reducing the Frequency of Cesarean Section. International Journal of Biomedicine. 2021;11(2):156-159. doi:10.21103/Article11(2)_OA6

\section{Abbreviations}

CNS, central nervous system; CS, cesarean section: ECS, emergency cesarean section; GDM, gestational diabetes mellitus; PL, programmed labor; PCS, planned cesarean section; RDS, respiratory distress syndrome.

\section{Introduction}

Gestational diabetes mellitus (GDM) is associated with various maternal and neonatal complications. Women with GDM have a higher risk of cesarean delivery than women with normal glucose tolerance. Delivery in GDM, as a rule, is associated with a large number of interventions in the process of childbirth: preparation of the cervix, induction of labor, and instrumental delivery (both vaginal and cesarean sections). An increased rate of cesarean section in women with GDM has been mentioned in many studies. ${ }^{(1-5)}$ The frequency of both planned and emergency abdominal delivery, according to the literature, 
is influenced by the following factors as parity: obesity, scar on the uterus after the previous CS, fetal macrosomia. ${ }^{(5-8)}$

In primiparous women, the risk of CS increases 3.9-4.6 times; with a combination of obesity and GDM - at least 2.25 times; with a combination of a scar on the uterus and GDM almost 5 times. ${ }^{(5,6,9-11)} \mathrm{CS}$ in GDM is considered as a method of preventing fetal injury. Modern measures for the prevention of fetal injury in GDM include planned abdominal delivery if the weight of the fetus exceeds $4500 \mathrm{~g}$, as well as induction of labor if the gestational age is more than 39 weeks and the weight of the fetus is more than the 95th percentile. ${ }^{(7)}$

According to Radzinsky et al. ${ }^{(12)}$ and Savicheva et al., ${ }^{(13)}$ PL accounts for an increasing share in the structure of delivery methods. Among GDM patients, in whom the PL protocol was applied, fetal macrosomia was 1.4 times more frequent; diabetic fetopathy - 1.5 times; obesity - 1.3 times, compared with patients with spontaneous onset of labor. However, the overall frequency of abdominal delivery was lower in the group with PL. ${ }^{(6,12,13)}$

Thus, the literature data demonstrate the high significance of the PL method with a clear selection of indications as the optimal method of delivery of pregnant women with GDM in the absence of absolute indications for CS.

The aim of this study was to investigate the perinatal outcomes of delivery by various methods in patients with GDM.

\section{Material and Methods}

The study included 403 pregnant women (gestational age of 37.0-41.0 weeks) with GDM and 68 without disorders of carbohydrate metabolism, who gave birth from the second quarter of 2018 to the third quarter of 2020 in the maternity ward of the City Clinical Hospital No. 29 named after N.E. Bauman. This was a prospective case-control study.

All patients with GDM were divided into 2 groups. Group 1 included 187 patients receiving insulin therapy; Group 2 included 216 patients receiving a well-balanced diet. A third group, Group 3, consisted of 68 pregnant women without disorders of carbohydrate metabolism.

The study was conducted in accordance with the ethical principles of the WMA Declaration of Helsinki (1964, ed. 2013) and was approved by the Ethics Committee of the RUDN University. Written informed consent was obtained from all participants.

Inclusion criteria were full-term pregnancy, cephalic presentation, and singleton pregnancy. Exclusion criteria were multiple pregnancy, premature birth, and breech presentation of the fetus. The diagnosis of GDM was based on the clinical recommendations of the $\mathrm{MH}$ of $\mathrm{RF}^{\left({ }^{(14)}\right.}$ The women were questioned with the aim of assessing 1) family history of disorders of carbohydrate metabolism and obesity; 2) chronic somatic and gynecological diseases; 3 ) reproductive history; and 4) complications of current pregnancy, the timing of GDM detection.

The condition of newborns was assessed in the first minutes of life, in the first day of life and in the early neonatal period. The assessment of the newborns' condition included: 1) measurement of anthropometric parameters (weight, height, head circumference, chest circumference); 2) the presence or absence of phenotypic signs of diabetic fetopathy, such as macrosomia, disproportionate physique, morpho-functional immaturity, moonlike face, cardiomegaly, splenomegaly, hepatomegaly, hypertrichosis, hyperbilirubinemia, hypoglycemia, neonatal CNS depression; 3) assessment of the Apgar score (at 1 minute and 5 minutes after birth); 4) the need for respiratory support and its duration, the duration of hospital stay, transfer to the second stage of nursing; 6) birth trauma; and 7) perinatal brain damage.

Macrosomia was defined as a birth weight greater than or equal to $4000 \mathrm{~g}$. The blood glucose concentration in newborns was measured 1 or more times a day, depending on the condition of the newborn, using a Glucometer "Accu-Chek Active New"(Switzerland) and visual test strips "Accu-Chek." Hypoglycemia was defined as blood glucose concentration $<2.6 \mathrm{mmol} / \mathrm{L}$ at any time after birth.

The level of total bilirubin in the blood serum of newborns was determined on a BF-TsN-01Bilirubinometer (Belarus) by the method of reagentless two-wave photometry. Hyperbilirubinemia was defined as serum concentration of total bilirubin $>256 \mu \mathrm{mol} / \mathrm{L}$.

Statistical analysis was performed using the Statistica 8.0 software package (StatSoft Inc, USA). Baseline characteristics were summarized as frequencies and percentages for categorical variables and as means and standard error of the mean (SEM) for continuous variables. Differences of continuous variables were tested by the Mann-Whitney U-test. Group comparisons with respect to categorical variables are performed using using the chi-square test or, alternatively, Fisher's exact test. A value of $P<0.05$ was considered statistically significant.

\section{Results and Discussion}

In Group 1, the methods of delivery were as follows: spontaneous delivery $(n=68), \operatorname{PL}(n=98), \operatorname{PCS}(n=17)$, and the emergency CS $(n=4)$ (Figure 1). In Group 2, the methods of delivery were as follows: spontaneous delivery (114), PL $(\mathrm{n}=83)$, and PCS $(\mathrm{n}=19)$ (Figure 2).

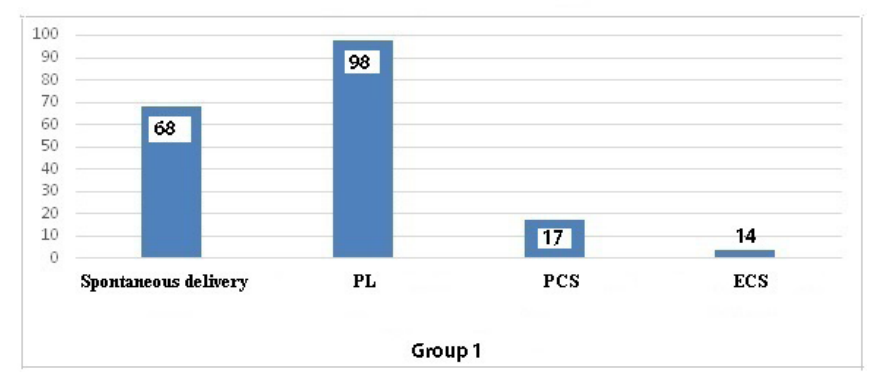

Fig.1. The methods of delivery in Group 1

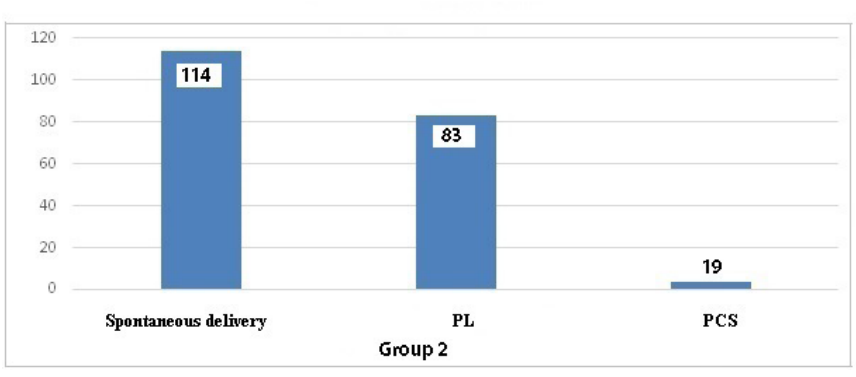

Fig.2. The methods of delivery in Group 2 
The main indicators of the health status of newborns in the early neonatal period were assessed taking into account the methods of delivery (PL, CS, spontaneous delivery).

The 1-minute Apgar score in newborns from mothers of Groups 1 and 2 was higher at the PL, compared with PCS. The 5-minute Apgar score in newborns from mothers of Group 2 was also statistically significantly higher at the PL, compared with PCS (Table 1). The data obtained indicate a better adaptation of children from mothers with GDM in the first minutes after birth at the PL, compared with abdominal delivery.

Table 1.

The Apgar score in newborns depending on the methods of delivery

\begin{tabular}{|c|c|c|c|c|}
\hline & $\begin{array}{c}\text { Spontaneous } \\
\text { delivery }\end{array}$ & PL & PCS & ECS \\
\hline \multicolumn{6}{|c|}{ The 1-minute Apgar score } \\
\hline Group 1 & $\begin{array}{c}8.3 \pm 0.6 \\
(\mathrm{n}=68)\end{array}$ & $\begin{array}{c}8.2 \pm 0.7^{*} \\
(\mathrm{n}=98)\end{array}$ & $\begin{array}{c}7.9 \pm 0.5^{*} \\
(\mathrm{n}=17)\end{array}$ & $\begin{array}{c}8.0 \pm 0.8 \\
(\mathrm{n}=4)\end{array}$ \\
\hline
\end{tabular}

\begin{tabular}{|c|c|c|c|c|}
\hline Group 2 & $\begin{array}{c}8.5 \pm 0.5 \\
(\mathrm{n}=114)\end{array}$ & $\begin{array}{c}8.3 \pm 0.7^{*} \\
(\mathrm{n}=83)\end{array}$ & $\begin{array}{c}7.8 \pm 0.6^{*} \\
(\mathrm{n}=19)\end{array}$ & - \\
\hline Group 3 & $8.7 \pm 0.4$ & $8.8 \pm 0.6$ & 0 & - \\
\hline
\end{tabular}

\begin{tabular}{|c|c|c|c|c|}
\hline \multicolumn{5}{|c|}{ The 5-minute Apgar score } \\
\hline Group 1 & $8.9 \pm 0.7$ & $8.8 \pm 0.7$ & $8.6 \pm 0.7$ & $8.7 \pm 0.5$ \\
\hline Group 2 & $9.1 \pm 0.6$ & $9.0 \pm 1.2 *$ & $8.6 \pm 0.4^{*}$ & - \\
\hline Group 3 & $9.4 \pm 0.5$ & $9.2 \pm 0.7$ & 0 & - \\
\hline
\end{tabular}

The incidence of hypoglycemia in newborns from mothers of all groups was minimal at the PL, including a statistically significant low rate in newborns from mothers of Group 1 (Table 2). Consequently, PL reduces the incidence of hypoglycemia in newborns, contributing to the formation of better adaptive mechanisms.

Table 2.

The incidence of hypoglycemia in newborns depending on the methods of delivery

\begin{tabular}{|c|c|c|c|c|}
\hline & $\begin{array}{c}\text { Spontaneous } \\
\text { delivery }\end{array}$ & PL & PGS & ECS \\
\hline \multicolumn{5}{|c|}{ The incidence of hypoglycemia (n, \%) } \\
\hline Group 1 & $14(20.5 \%)$ & $17(17.3 \%) *$ & $7(41.1 \%) *$ & $1(25,0 \%)$ \\
\hline Group 2 & $24(21.0 \%)$ & $16(19.2 \%)$ & $4(21.0 \%)$ & - \\
\hline Group 3 & $1(14.2 \%)$ & $2(3.3 \%)$ & - & - \\
\hline
\end{tabular}

Symptoms of neonatal CNS depression were significantly more common in newborns born by abdominal delivery from mothers with GDM (Table 3). Thus, in newborns from mothers of Group 1, this complication was found in $24.4 \%$ of the cases with PL and in $52.9 \%$ of the cases with PCS $(P=0.02)$. In newborns from mothers of Group 2, this complication was found in $20.4 \%$ of the cases with PL and in $47.3 \%$ of the cases with PCS $(P=0.01)$.

Table 3.

Symptoms of neonatal CNS depression in newborns depending on the methods of delivery

\begin{tabular}{|c|c|c|c|c|}
\hline & $\begin{array}{c}\text { Spontaneous } \\
\text { delivery }\end{array}$ & PL & PCS & ECS \\
\hline \multicolumn{5}{|c|}{ Symptoms of neonatal CNS depression (n, \%) } \\
\hline Group 1 & $20(29.4 \%)$ & $24(24.4 \%)^{*}$ & $9(52.9 \%)^{*}$ & $1(25.0 \%)$ \\
\hline Group 2 & $18(15.7 \%)$ & $17(20.4 \%) *$ & $9(47.3 \%)^{*}$ & - \\
\hline Group 3 & $3(5.0 \%)$ & - & - & - \\
\hline
\end{tabular}

Thus, when the 2 methods of delivery (PL and PCS) were compared, the health level of newborns was higher in PL. The data obtained are consistent with the opinion of P. Rozenberg that programmed labor is the optimal method for women with GDM. ${ }^{(15)}$ This technique reduces the level of neonatal morbidity and mortality in GDM. A similar opinion is shared by Biesty et al., who noted the comparability of perinatal outcomes in PL in women with GDM and without disorders of carbohydrate metabolism. ${ }^{(16)}$

In conclusion, PL in women with GDM reduces the incidence of the main complications of the early neonatal period: hypoglycemia and symptoms of neonatal CNS depression. Given the prevalence of favorable perinatal outcomes, PL may be considered more acceptable than abdominal delivery for women with GDM. By reducing the incidence of perinatal complications, PL may be a reserve for reducing the frequency of CS in GDM in the absence of absolute indications for abdominal delivery.

\section{Competing Interest}

The authors declare that they have no competing interests.

\section{Sources of Funding}

This paper has been supported by the RUDN University Strategic Academic Leadership Program,

\section{References}

1. Goldman M, Kitzmiller JL, Abrams B, Cowan RM, Laros RK Jr. Obstetric complications with GDM. Effects of maternal weight. Diabetes. 1991 Dec;40 Suppl 2:79-82. doi: 10.2337/ diab.40.2.s79.

"Corresponding author: Irina V. Bekbaeva. Peoples' Friendship University of Russia (RUDN University, Moscow, Russia. E-mail: iridescentgirl@yandex.ru 
2. Naylor CD, Sermer M, Chen E, Sykora K. Cesarean delivery in relation to birth weight and gestational glucose tolerance: pathophysiology or practice style? Toronto Trihospital Gestational Diabetes Investigators. JAMA. 1996 Apr 17;275(15):1165-70. PMID: 8609683.

3. Gorgal R, Gonçalves E, Barros M, Namora G, Magalhães A, Rodrigues T, Montenegro N. Gestational diabetes mellitus: a risk factor for non-elective cesarean section. J Obstet Gynaecol Res. 2012 Jan;38(1):154-9. doi: 10.1111/j.14470756.2011.01659.x.

4. Boriboonhirunsarn D, Waiyanikorn R. Emergency cesarean section rate between women with gestational diabetes and normal pregnant women. Taiwan J Obstet Gynecol. 2016 Feb;55(1):64-7. doi: 10.1016/j.tjog.2015.08.024.

5. Zeki R, Oats JJN, Wang AY, Li Z, Homer CSE, Sullivan EA. Cesarean section and diabetes during pregnancy: An NSW population study using the Robson classification. J Obstet Gynaecol Res. 2018 May;44(5):890-898. doi: 10.1111/ jog. 13605 .

6. Radzinsky VE, Botasheva TL, Papysheva OV. Obesity. Diabetes. Pregnancy. Versions and contraversions. Clinical practices. Perspectives. M: GEOTAR-Media, 2020.

7. Zeki R, Wang AY, Lui K, Li Z, Oats JJN, Homer CSE, Sullivan EA. Neonatal outcomes of live-born term singletons in vertex presentation born to mothers with diabetes during pregnancy by mode of birth: a New South Wales populationbased retrospective cohort study. BMJ Paediatr Open. 2018 Jan 30;2(1):e000224. doi: 10.1136/bmjpo-2017-000224.

8. Zhou X, Chen R, Zhong C, Wu J, Li X, Li Q, et al, Maternal dietary pattern characterised by high protein and low carbohydrate intake in pregnancy is associated with a higher risk of gestational diabetes mellitus in Chinese women: a prospective cohort study. Br J Nutr. 2018 Nov;120(9):10451055. doi: $10.1017 / \mathrm{S} 0007114518002453$.

9. Orazmuradov AA, Papysheva OV, Soyunov MA, Bekbaeva IV, Arakelyan GA, Haddad Kh, Lopatin AM, Kyrtikov SI, Zokirova NM, Mukovnikova EV. Peculiar
Properties of Pregnancy and Childbirth in Women with Gestational Diabetes Mellitus Depending on Body Weight. Systematic Reviews in Pharmacy. 2020;11(11):1338-1340.

10. Orazmuradov AA, Savenkova IV, Arakelyan GA, Loginova EV, Lukanovskaya OB, Kotaysh GA. Modern Notions of Health of Newborns from Mothers with Gestational Diabetes Mellitus. Systematic Reviews in Pharmacy. 2020;11(3):526-531.

11. Orazmuradov AA, Savenkova IV, Arakelyan GA, Damirova SF, Papysheva OV, Lukanovskaya OB. Peculiar Properties of Metabolism Women with Gestational Diabetes Mellitus. Systematic Reviews in Pharmacy. 2020;11(2):237-241.

12. Radzinsky VE., Papysheva OV, Esipova LN, Startseva NM, Kotaysh GA, Lukanovskaya OB. The effectiveness of programmed labor in gestational diabetes mellitus in reducing the frequency of caesarean section. Akusherstvo i Ginekologiia: Novosti, Mneniia, Obuchenie. 2019;(3(25)):2531. doi: 10.24411/2303-9698-2019-13004.

13. Savicheva AM, Papysheva OV, Startseva NM, Ordiyants IM. Programmed labor and metabolic homeostasis in gestational diabetes mellitus. Akusherstvo i Ginekologiia: Novosti, Mneniia, Obuchenie. 2018;6(3, Suppl):46-50. doi: 10.24411/2303-9698-2018-13907.

14. Gestational diabetes mellitus. Diagnostics, treatment, obstetric tactics, postpartum follow-up. Clinical guidelines. Russian Association of Endocrinologists. Russian Society of Obstetricians and Gynecologists. Moscow, 2020.

15. Rozenberg P. [In case of fetal macrosomia, the best strategy is the induction of labor at 38 weeks of gestation]. J Gynecol Obstet Biol Reprod (Paris). 2016 Nov;45(9):10371044. doi: 10.1016/j.jgyn.2016.09.001. [Article in French]. 16. Biesty LM, Egan AM, Dunne F, Dempsey E, Meskell P, Smith V, Ni Bhuinneain GM, Devane D. Planned birth at or near term for improving health outcomes for pregnant women with gestational diabetes and their infants. Cochrane Database Syst Rev. 2018 Jan 5;1(1):CD012910. doi: 10.1002/14651858. CD012910. 